\title{
Optimization of special freight wagons with small wheel diameter
}

\author{
A. Rindi, D. Fioravanti, L. Pugi, M. Rinchi \& J. Auciello \\ Università degli Studi di Firenze, Dip. Energetica "Sergio Stecco”, Italy
}

\begin{abstract}
A better integration and interoperability between rail and road transportation is a key factor in order to reduce pollution and increase railway freight traffic.

Development of special freight wagons like "SAADKMS" for the transportation of trucks by railway is a successful solution that is meeting an increasing consensus and popularity among many European countries. In order to accelerate truck loading on wagons and reduce the limitation of normal clearance (structure/vehicle/loading gauges) it is necessary to reduce the wheel diameter as much as possible. This is not a drawback-free solution since an excessive reduction of wheel diameter involves many troubles concerning the stability of the vehicle, maximum axle load, wear of bearings and rolling surfaces of rails and axles. Also designing the braking system is very complicated because the reduced number of encumbrances available makes the placement of internal disks on the axles difficult.

In order to solve these problems a very original solution concerning wheelset, wheel profiles and more general bogie design have been applied in the development of "SAADKMS" freight wagons so the resulting vehicle is very different from the conventional one. As a matter of fact, many past experiences and know-how for conventional freight wagons are not applicable for this kind of application, so numerical simulations are very important to deeply understand the behaviour of the system and propose criteria for further optimization.

The authors of this paper have developed models on commercial multibody software in order to simulate the behaviour of the "SAADKMS" freight wagon in different conditions (stability, steering performances). Also important results such as position of the contact point or wear-number are shown to be useful parameters for further optimization of the rolling surface profiles.

Keywords: SAADKMS, wheel, rail, wear, freight, wagon, intermodal.
\end{abstract}




\section{Introduction: the SAADKMS inter-modal freight wagon}

SAADKMS inter-modal freight wagon has been developed by Bombardier Transportation for the transportation of trucks by railway.

Design specifications concerning encumbrances and loading procedures has lead to a drastic reduction of wheel rolling radius to about $180-190 \mathrm{~mm}$.

According to Hertz contact theory [1] wheel rolling radius reduction involves a lower contact area and a higher stress of wheel material as can be shown by the following equation (simplified formulation modelling the contact between a cylinder and a planar surface):

$$
p_{\max }=\frac{2 F}{\pi b l} ; \quad b=\sqrt{\frac{4 F}{\pi l} \cdot \frac{2 \boldsymbol{r}\left(1-v^{2}\right)}{E}} ;
$$

where $p_{\max }$ is the maximum contact pressure, $F$ represents the normal force between wheel and rail, $l$ and $b$ are respectively the length and the semi width of the contact area and $\boldsymbol{r}$ is the wheel radius.

As a consequence normal load has to be divided on a higher number of axles. Also reduced wheel rolling radius involves different behaviours concerning stability (hunting) of the bogie respect to a standard freight wagon. In fact, as stated by the simplified model of Klingel $[2,3]$, the hunting frequency of a single axle with a conical profile is influenced by a factor that is approximately equal to " $\boldsymbol{r}^{-1 / 2}$ " as shown in figure 1 .

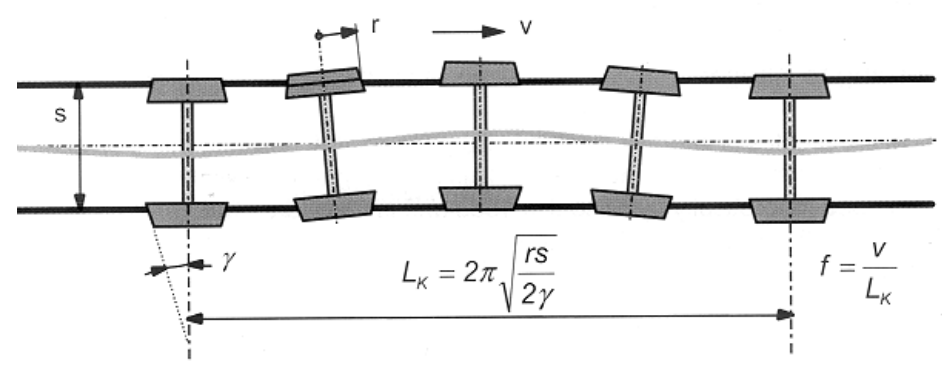

Figure 1: Axle hunting according simplified Klingel model.

SAADKMS bogie has been designed as a compromise between different engineering exigencies as visible in figure 2:

1) Four axles on every bogie in order to obtain a better distribution of normal loads.

2) Two lower frames: every lower frame is composed by two axles connected to two longitudinal elements by four spherical joints that assure an elevate angular clearance, in order to improve the steering performances of the wagon on small radius curves. 
3) An intermediate frame is suspended on the lower frames trough eight rubber deformable elements that are able to carry both vertical and longitudinal loads. Friction dampers/bumstops complete this first suspension stage.

4) Carbody is then suspended on the intermediate frames through a second stage of helical springs completed by friction elements that introduce damping against hunting. Longitudinal forces are transmitted by the central bearing.

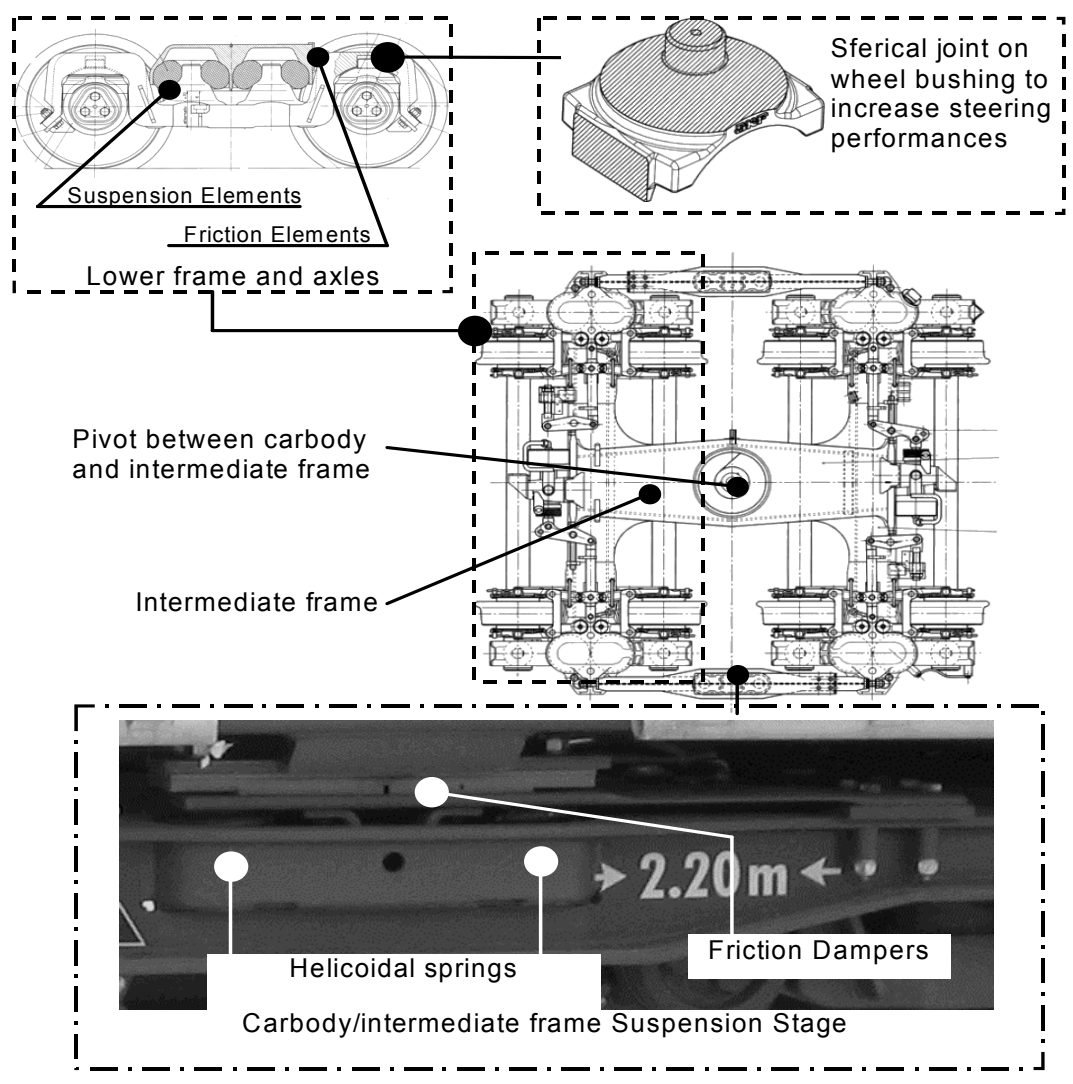

Figure 2: SAADKMS secondary suspension stage [4].

\section{ADAMS model design and validation}

Authors have developed a multibody model of the SAADKMS freight wagon in order to understand how different operating conditions and optimization factors may influence stability, steering and wearing of the tested vehicle. Authors have decided to develop the model using MSC.ADAMS/Rail ${ }^{\mathrm{TM}}$, one of the most 
diffused and advanced tool for multibody simulation of railway vehicles. In table 1 a brief list of the most significant eigen frequencies of the multibody model of SAADKMS wagon is presented.

Table 1: $\quad$ The most significant eigen frequencies of the SAADKMS wagon.

\begin{tabular}{|r|l|l|l|l|}
\hline $\begin{array}{r}\text { MO. } \\
\text { NB. }\end{array}$ & UND. NAT. & FAMPING RATIO & REAL PART & IMAGINARY \\
\hline \hline 51 & $2.142070 \mathrm{E}+000$ & $2.910582 \mathrm{E}-001$ & $-6.234670 \mathrm{E}-001$ & $\pm 2.049330 \mathrm{E}+000$ \\
\hline 52 & $3.753565 \mathrm{E}+000$ & $3.243317 \mathrm{E}-001$ & $-1.217400 \mathrm{E}+000$ & $\pm 3.550660 \mathrm{E}+000$ \\
\hline 53 & $4.498930 \mathrm{E}+000$ & $3.471137 \mathrm{E}-001$ & $-1.561640 \mathrm{E}+000$ & $\pm 4.219200 \mathrm{E}+000$ \\
\hline 54 & $4.636812 \mathrm{E}+000$ & $2.242597 \mathrm{E}-001$ & $-1.039850 \mathrm{E}+000$ & $\pm 4.518710 \mathrm{E}+000$ \\
\hline 55 & $5.345492 \mathrm{E}+000$ & $2.058501 \mathrm{E}-001$ & $-1.100370 \mathrm{E}+000$ & $\pm 5.231010 \mathrm{E}+000$ \\
\hline 56 & $2.024580 \mathrm{E}+001$ & $8.340102 \mathrm{E}-001$ & $-1.688520 \mathrm{E}+001$ & $\pm 1.117060 \mathrm{E}+001$ \\
\hline 57 & $2.024638 \mathrm{E}+001$ & $8.326873 \mathrm{E}-001$ & $-1.685890 \mathrm{E}+001$ & $\pm 1.121130 \mathrm{E}+001$ \\
\hline 58 & $1.764043 \mathrm{E}+001$ & $4.554045 \mathrm{E}-001$ & $-8.033530 \mathrm{E}+000$ & $\pm 1.570500 \mathrm{E}+001$ \\
\hline 59 & $1.805762 \mathrm{E}+001$ & $4.271918 \mathrm{E}-001$ & $-7.714070 \mathrm{E}+000$ & $\pm 1.632700 \mathrm{E}+001$ \\
\hline 60 & $2.176496 \mathrm{E}+001$ & $1.740655 \mathrm{E}-001$ & $-3.788530 \mathrm{E}+000$ & $\pm 2.143270 \mathrm{E}+001$ \\
\hline $61-67$ & $2.178060 \mathrm{E}+001$ & $1.756940 \mathrm{E}-001$ & $-3.826720 \mathrm{E}+000$ & $\pm 2.144180 \mathrm{E}+001$ \\
\hline $68-75$ & $2.870752 \mathrm{E}+001$ & $4.527978 \mathrm{E}-001$ & $-1.299870 \mathrm{E}+001$ & $\pm 2.559600 \mathrm{E}+001$ \\
\hline
\end{tabular}

Simulation involves simplifications and calibrations that have to be carefully evaluated in order to avoid unacceptable errors in results. Some factors as friction between rolling surfaces or the behaviour of friction dampers/end stops often introduce heavy approximation in the response of the system especially when $\mathrm{rapid} /$ heavy transients are involved. So the authors have decided to calibrate and validate their model by a double comparison with available experimental data kindly supplied by SBB and simulation results of a benchmark model of the vehicle developed by Trenitalia using a different software, Vampire $^{\mathrm{TM}}$ from AEA Technology. First the model results have been calibrated on experimental data using record from a steering test carried on by SBB. Main features of the test are described in table 2.

Table 2: $\quad$ Experimental test features.

\begin{tabular}{|c|c|}
\hline Line/Track Design & Freight Wagon \\
\hline \multirow{2}{*}{$\begin{array}{l}\text { Line design: straight track of } 100 \mathrm{~m} \text {, blending } \\
\text { curvature tracks (clothoid) of about } 70 \mathrm{~m} \text {, } \\
\text { constant curvature length of } 310 \mathrm{~m} \text { with a radius } \\
\text { of } 360 \mathrm{~m} \text { followed by a second blending track of } \\
70 \mathrm{~m} \text {. and a final straight path of } 50 \mathrm{~m}\end{array}$} & Speed: $80 \mathrm{~km} / \mathrm{h}$ \\
\hline & Cant deficiency: $0.5 \mathrm{~m} / \mathrm{s}^{2}$ \\
\hline Rail Profile: UIC 60 (wearied) & \multirow{2}{*}{$\begin{array}{l}\text { Wheel profiles: SBB } 32-3 \\
75^{\circ} \text { (wearied) }\end{array}$} \\
\hline Track gauge: $1439.7 \mathrm{~mm}$ & \\
\hline Super elevation: $135 \mathrm{~mm}$ & \multirow{2}{*}{$\begin{array}{l}\text { Friction factor } \\
\text { distribution: } 0.2 \text { on flange } \\
0.4 \text { on conical surf } \\
\end{array}$} \\
\hline Rail inclination: $1: 40$ & \\
\hline
\end{tabular}


The tested SBB vehicle was equipped with sensors in order to measure lateral and vertical forces exchanged through the wheel-rail interface.

In figure 3(a-c) some experimental are compared (lateral forces behaviour on the first axle vehicle according motion sense)

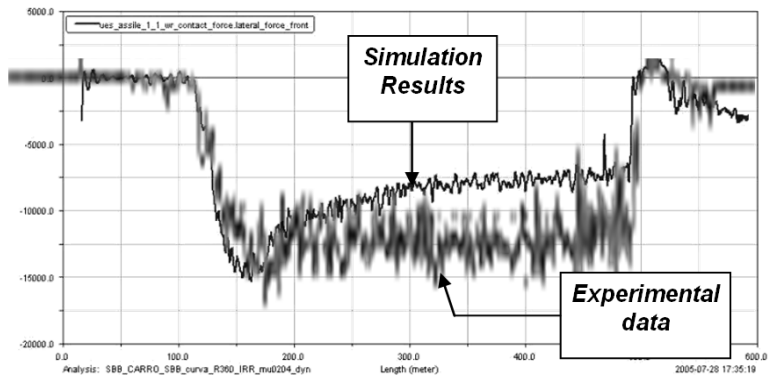

(a)

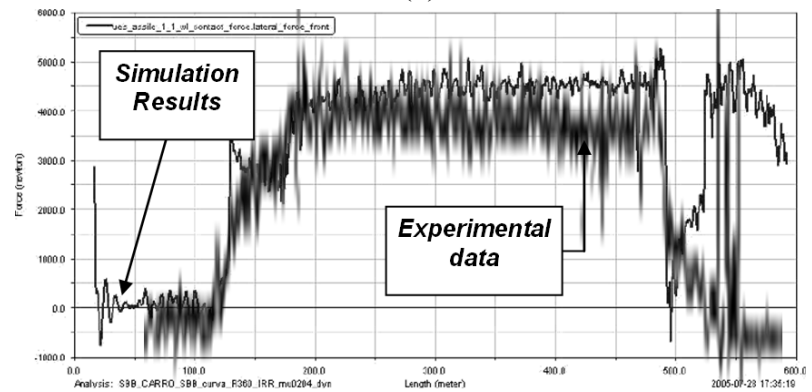

(b)

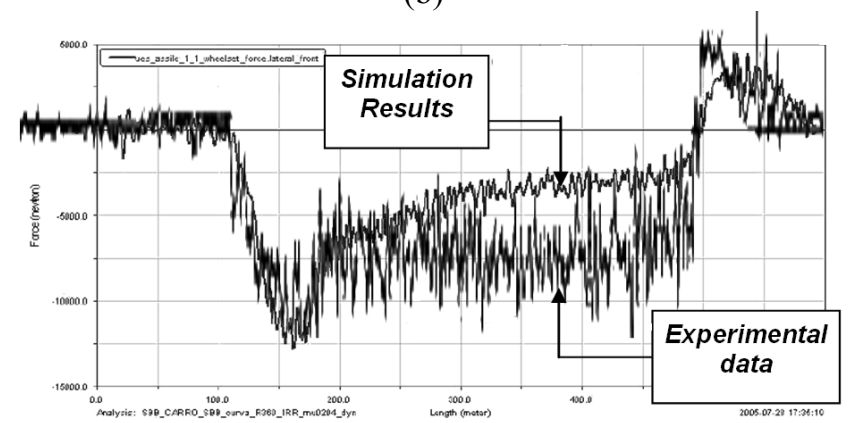

(c)

Figure 3: Lateral forces on (a) the external wheel of the first axle, (b) the internal wheel of the first axle and (c) the first axle (sum of internal and external wheel forces), comparison between experimental data and simulation results.

Simulation model show a good agreement with experimental data. Main differences are due to noise on the experimental data that were available only in paper-format and to heavy uncertainty in the modelling of both friction damper and wheel flange lubrication. In fact, it's very difficult to exactly foresee how the 
lubricant on the flange influences the adhesion factor distribution along the wheel surface.

Further validation activities have involved the comparison between ADAMS model of the wagon developed by the authors and the VAMPIRE one.

Comparison between the two different models has shown a good agreement in several benchmark tests even if their internal layouts presented some differences mainly in the formulation/implementation of simulation codes. This result can be easily explained since in the comparison between simulation models, many uncertainties have been removed: for example, both models suppose the same adhesion factor distribution on wheel profiles and the same design of the track, without any difference regarding irregularities.

In table 3 we have showed the feature of one of the most significant benchmark test that the authors have carried on to compare the results of the two models: a run at various speed on a switch.

Simulations have been repeated using different wheel profiles that have been used for SAADKMS freight wagons:

1) The standard SBB $32-375^{\circ}$ profile (the first used on SAADKMS freight wagons).

2) The optimized profile SBB ROLA Neu.

3) The optimized profile OBB SBB 32-3 FSDR3.

Table 3: $\quad$ Experimental test features.

\begin{tabular}{|c|c|}
\hline Line/Track Design & Freight Wagon \\
\hline \multirow{2}{*}{$\begin{array}{l}\text { Line design: straight track of } 10 \mathrm{~m} \text {, curve with } \\
\text { constant curvature length of } 25 \mathrm{~m} \text { with a radius } \\
\text { of } 160 \mathrm{~m} \text { followed by a second curve length of } \\
25 \mathrm{~m} \text { and a curvature radius of }-160 \mathrm{~m} \text { (opposite } \\
\text { curvature), }\end{array}$} & Speed: $10 / 40 \mathrm{~km} / \mathrm{h}$ \\
\hline & $\begin{array}{l}\text { Cant deficiency: variable } \\
\text { according vehicle speed }\end{array}$ \\
\hline Rail Profile: UIC 50 (NEW) & $\begin{array}{l}\text { Wheel profiles: SBB 32-3 } \\
75^{\circ} / \text { SBB ROLA Neu } \\
\text { OBB SBB 32-3 FSDR3 }\end{array}$ \\
\hline Track gauge: Standard & \multirow{3}{*}{$\begin{array}{l}\text { Friction factor } \\
\text { distribution: } 0.2 \text { on flange } \\
0.4 \text { on conical surf }\end{array}$} \\
\hline Super elevation: 0 & \\
\hline Rail inclination: $1: 20$ & \\
\hline
\end{tabular}

In figures $4(\mathrm{a}-\mathrm{d})$ some results concerning lateral forces on the first axle during a run at $40 \mathrm{~km} / \mathrm{h}$ are shown. Both the models are able to simulate the improvements in the axle behaviour with wear-optimized wheel profiles. Results also agree with experimental evidences that show the same performance improvements of optimized profiles compared with the standard SBB $32-375^{\circ}$.

Some unavoidable differences between results of the two models are mainly due to different contact formulation and friction distribution along wheel profiles. 


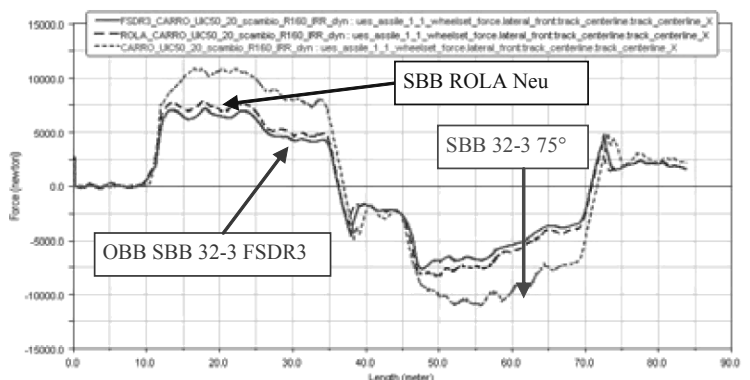

(a)

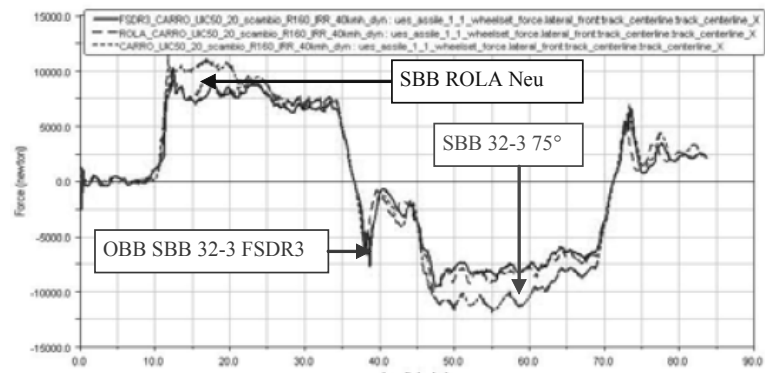

(b)

in

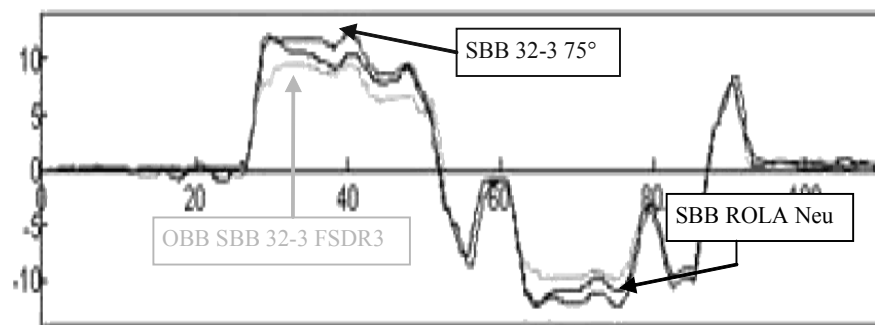

(c)

m

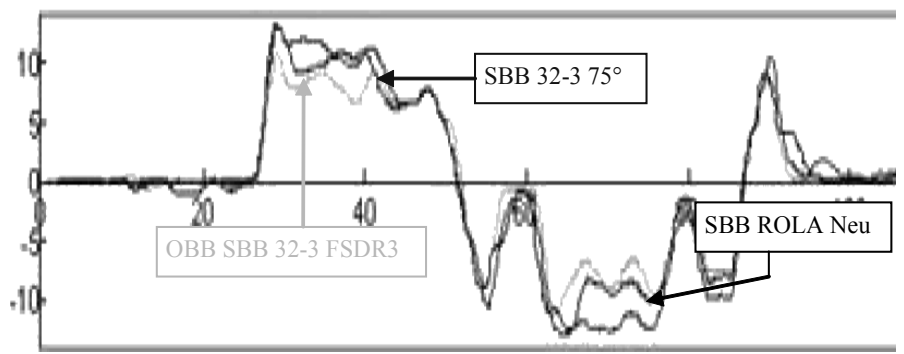

(d)

Figure 4: Lateral forces $(\mathrm{N})$ on the first axle with a travelling speed of (a) $10 \mathrm{~km} / \mathrm{h}$ and (b) $40 \mathrm{~km} / \mathrm{h}$ (ADAMS model results). Lateral forces (kN) on the first axle with a travelling speed of (c) $10 \mathrm{~km} / \mathrm{h}$ and (d) $40 \mathrm{~km} / \mathrm{h}$ (VAMPIRE model results). 


\section{Simulation and optimization results}

The most significant results concerning the optimization of the dynamical behaviour of the wagon have been first discovered during the design and the validation phase of the model and then confirmed once the model was completed by simulation results:

1. Sensitivity of ride quality and safety from friction factor of damping elements.

2. Importance of good lubrication of wheel flange and uncertainties due to an unpredictable distribution of the friction factor along the wheel profiles.

3. Wheel profile optimization.

\subsection{Sensitivity from damper friction factor}

In SAADKMS bogies damping is mainly introduced using friction elements. Both stability and steering performances are heavily affected from fluctuation of the damper friction factor. Experimental data from specially equipped test rig [5], visible in figure 5, show a strong dependency of the friction factor from temperature since fluctuations of few Celsius causes relative variations of friction of about $10-20 \%$. Also a near to hyperbolic relation between wear and friction factor is clearly visible.

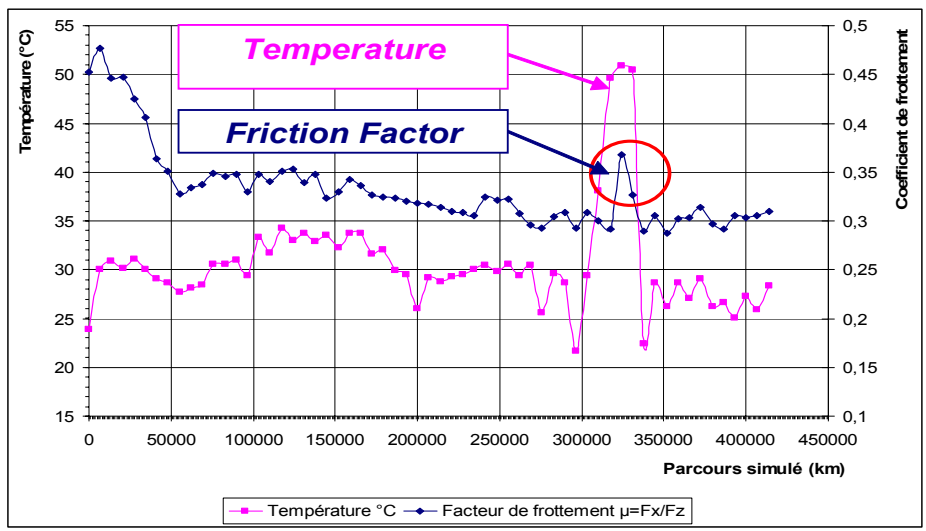

Figure 5: Friction fluctuations associated to different wear and temperature conditions [5].

During the calibration of the wagon model a medium/heuristic value of this friction factor has been chosen, however it's very difficult to predict the right value in operating conditions. So one of the hints from simulation activities it's to use more stable viscous anti-yaw damper in order to improve both stability and steering performances in a reliable manner. 


\subsection{Wheel flange lubrication}

Actually wheel flange lubrication is adopted on SAADKMS freight wagons. Lubrication reduces flange wear and assures a better stability. In fact, as reported by simplified models often used in literature (see $[1,2,6]$ ), the critical ratio to avoid derailment between horizontal forces " $\boldsymbol{Y}$ " and vertical forces " $\boldsymbol{Q}$ " is negatively affected by the friction factor as visible in equation (2). In this equation " $\beta$ " represents the geometrical flange conicity and " $\varphi$ " the friction angle defined by (3).

$$
\begin{aligned}
& \text { derailment occurs if }: \frac{Y}{Q}>\frac{\sin \beta-\tan \varphi \cos \beta}{\tan \varphi \sin \beta+\cos \beta}=\tan (\beta-\varphi) \\
& f(\text { friction factor })=\tan \varphi
\end{aligned}
$$

Simulation results show a strong sensitivity in the dynamical behaviour from friction factor distribution along wheel profiles. In particular performances are affected by the friction factor in the lubricated surfaces and by the extension of these patches especially in the smoothing fillet between the conical zone of the wheel and the flange. According simulation results quality and reliability of lubrication with different operating conditions such as temperature may be critical factors that have to be deeply investigated.

\subsection{Wheel profile optimization}

As clearly visible in figure $7(\mathrm{a}-\mathrm{d})$ optimized wheel profiles may increase the dynamical performances of the wagon. In particular the OBB SBB 32-3 FSD R3 has showed the best performances.

In figure 6 the standard SBB $32-75^{\circ}$ profile is compared with the optimized one: the optimized profile has a slightly higher conicity and an increased flange clearance in order to improve steering performances of wheels.

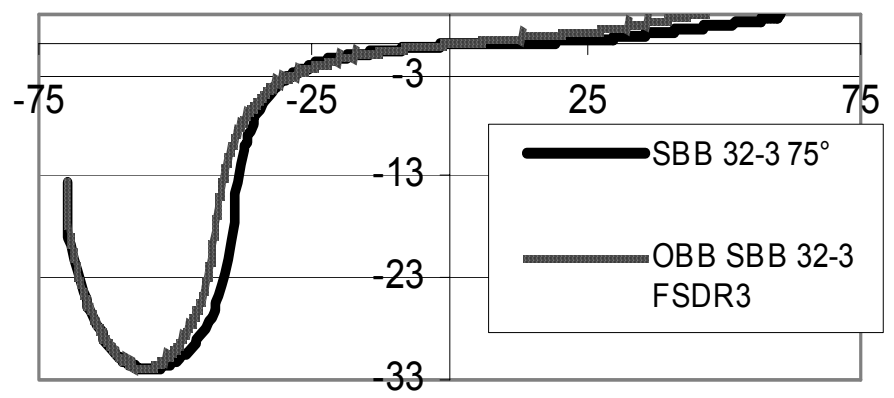

Figure 6: Comparison between standard SBB 32-3 $75^{\circ}$ profile and the optimized OBB SBB 32-3 FSD R3. 


\section{Conclusion and future hints}

Authors have developed and validated a multibody model of the SAADKMS freight wagon and are still working in order to improve model performances and results. In particular they are still working to develop a third model of the wagon using another well known simulation tool, the Intec-Simpack ${ }^{\mathrm{TM}}$ package.

In addition, authors are applying innovative techniques based on damage/wear number criteria [7] in order to understand how further optimization for different railway profiles and inclinations may be carried on.

\section{Acknowledgements}

Research activities in the railway sector often involve the availability of technical information, experimental data, and a continuous feedback from experienced users. Cooperation is a key-word for the success of research activities. The authors wish to thanks all the technicians, the researchers and the managers that have supported in different way the activities described in this paper. In particular we remember Ing. Desideri (Trenitalia SPA), Ing. Muller (SBB).

\section{References}

[1] J.J. Kalker, "Three-Dimensional Elastic Bodies in Rolling Contact", Kluwert Academic Publishers, 1990.

[2] Esveld, Coenraad, "Modern Railway Track. MRT-Productions", Zaltbommel, The Netherlands, second edition, 2001, ISBN 90-800324-3-3.

[3] Romano Panagin, "La dinamica del veicolo ferroviario" ed. Levrotto \& Bella 1997

[4] Technical documentation of Trenitalia SPA

[5] ROLA Project Technical Documentation

[6] A.H. Wickens,"Fundamentals of railway vehicle dynamics" Taylor and Francis 2003

[7] K.J. Hewitt, “A Model for the Prediction of Rail Wear". AEA Technology Rail report RR-PRJ-70012-WEAR, September 1995. 